\title{
Los estatutos de arriendo de un monopolio concejil: los hostales de Villarreal de Huerva (año 1457)*
}

\author{
The renting rules of a municipal monopoly: \\ the lodging houses of Villarreal de Huerva (year 1457)
}

DAVID PARDILLOS MARTÍN**

\begin{abstract}
RESUMEN
En el presente trabajo se presentan y analizan unas ordenanzas municipales inéditas que regularon, a mediados del siglo XV, el arriendo y la explotación de las hosterías de la localidad aragonesa de Villarreal de Huerva, municipio que formó parte durante la Edad Media de la Comunidad de aldeas de Daroca. Dichas ordenanzas se conservan en un protocolo del notario darocense Juan Ram del año 1457 que se encuentra ubicado en el Archivo de Protocolos Notariales de
\end{abstract} Zaragoza.

\section{PALABRAS CLAVE}

Sociedad. Documentación. Aragón. Villarreal de Huerva. Siglo XV.

\begin{abstract}
In the present research work some unpublished municipal ordinances which, in the middle of the fifteenth century, regulated the renting and the exploitation of lodging houses in Villarreal de Huerva are presented and analyzed. This aragonese locality belonged to the Community of Daroca's villages during the Middle Age. These ordinances are remained in a protocol of the darocense notary Juan Ram of the year 1457. This protocol is kept in the Notarial Archives of Saragossa.
\end{abstract}

\section{KEY WORDS}

Society. Documentation. Aragon. Villarreal de Huerva. Fifteenth century.

* Fecha de recepción del artículo: 2009-02-25. Fecha de aceptación del artículo: 2009-03-26.

** Universidad de Zaragoza. Facultad de Filosofía y Letras. Departamento de Historia Medieval, CC. y TT. Historiográficas y Estudios Árabes e Islámicos. C/ Pedro Cerbuna, $n^{\circ} 12,50.009$, Zaragoza. Correo electrónico: davidpm@unizar.es. Este trabajo se ha realizado en el seno del Grupo de Investigación de Excelencia C.E.M.A. que financia el Departamento de Ciencia, Tecnología y Universidad del Gobierno de Aragón. 
Entre la documentación del Archivo Histórico de Protocolos Notariales de Zaragoza (A.H.P.Z.) se encuentra el fondo notarial del escribano darocense Juan Ram. En el registro de su protocolo del año 1457 se han localizado unas ordenanzas municipales inéditas que regulaban la explotación del hospedaje de la actual localidad de Villarreal de Huerva ${ }^{1}$ a mediados del siglo XV. Interesado como estoy en el estudio de la sociedad aragonesa bajomedieval en el entorno de la Comunidad de aldeas de Daroca, me ha parecido oportuno dar a conocer esta documentación y así ponerla a disposición de los investigadores e investigadoras que centran sus trabajos en dicho período.

Las citadas ordenanzas son el colofón a dos documentos que reglamentan el arrendamiento de las hospederías que el concejo de la citada aldea realizó en octubre de 1457 a dos vecinos de la localidad. El cuerpo dispositivo de estas ordenanzas, que consta de ocho puntos o capítulos a los que hay que sumar otros cuatro que se especifican en el contrato de arrendamiento, regula, como veremos, por un lado, las obligaciones de los hostaleros respecto a la explotación del monopolio y las sanciones por el mal uso de la concesión y, por otro, las sanciones a los vecinos del lugar que quebrantaran lo estipulado en dichas ordenanzas.

\section{LOS HOSTALES O DIVERSORIOS}

Acerca de los viajeros medievales, sus itinerarios, su hospedaje y los problemas derivados de sus desplazamientos existen, sobre todo, estudios vinculados a las grandes rutas comerciales ${ }^{2}$ y de peregrinación ${ }^{3}$. Desde siempre las personas, cuando se han desplazado, han precisado de un cobijo que les diera reposo tanto

\footnotetext{
1 Villarreal, hasta 1910. Villarreal de Huerva, desde 1920. Según UBIETO ARTETA, Antonio, Historia de Aragón. Los pueblos y los despoblados, Tomo III, Zaragoza, Anubar Ediciones, 1984, p. 1366.

2 Resulta imprescindible citar las actas de la XVI Semana de Estudios Medievales de Nájera, dedicadas al estudio del comercio en la Edad Media donde diferentes especialistas en la materia reflexionan sobre los espacios de comercio nacional e internacional, los protagonistas del mismo, los escenarios de intercambio, los medios de pago, las políticas comerciales de los reinos hispanos y los medios, técnicas y útiles de transporte. VV.AA., El comercio en la Edad Media. XVI Semana de Estudios Medievales, Logroño, Instituto de Estudios Riojanos, 2006.

3 Sobre la principal ruta de peregrinaje en la Península lbérica son fundamentales los trabajos recogidos en tres actas. La primera de ellas, la de la XX Semana de Estudios Medievales de Estella, que versa sobre el Camino de Santiago y la articulación del espacio hispánico, donde especialistas españoles y europeos abordaron el estudio de la organización del espacio en los diferentes ámbitos territoriales por los que discurría la ruta jacobea. VV.AA., El Camino de Santiago y la articulación del espacio hispánico. XX Semana de Estudios Medievales de Estella, Pamplona, Gobierno de Navarra, 1994. Resultan fundamentales las actas de la IV Semana de Estudios Medievales de Nájera, dedicada al estudio del Camino de Santiago en los siglos medievales donde, además de las reflexiones sobre el arte de viajar en la Edad Media, los trazados, la circulación de hombres, mercancías e ideas, se trata el tema del hospedaje, la alimentación y la atención de los peregrinos en la ruta jacobea. VV.AA., IV Semana de Estudios Medievales, Logroño, Instituto de Estudios Riojanos, 1994. Asimismo, las actas de la reunión científica llevada a cabo en Logroño en torno al Camino de Santiago y la sociedad medieval donde, para el tema que nos ocupa, resulta fundamental el trabajo de Luis Martínez García sobre el hospedaje en la ruta jacobea. MARTÍNEZ GARCÍA, Luis, «La hospitalidad y el hospedaje en el Camino de Santiago», en El Camino de Santiago y la sociedad medieval, Logroño, Instituto de Estudios Riojanos, 2000, pp. 97-110.
} 
a ellas como a sus monturas, cuando de éstas han hecho uso. A este efecto, los hostales y tabernas han cumplido la función de lugares donde poder comer, descansar y avituallarse.

En la Comunidad de Daroca, a pesar de no encontrarse excesivamente documentadas, no se duda de la existencia de hospederías en muchas de las aldeas de la Comunidad, sobre todo las más pobladas y las situadas en itinerarios especialmente transitados. Por el contrario, habría otras aldeas que, por su pequeño tamaño o por su situación geográfica inconexa fuera de los itinerarios de tránsito comunes, no dispondrían de hospederías al no precisarlas. En estas pequeñas aldeas, carentes de posadas donde alojarse, es donde se articularía un sistema de hospedaje claramente rudimentario. Los caminantes se recogían en casas particulares cuyos propietarios alquilaban algunas dependencias sobrantes para este fin y donde se proporcionaba al viajante y a sus monturas techo, cama y establo 4 . El resto de necesidades, la adquisición y la preparación de los productos habituales de su sustento diario o los gastos ocasionados para atender las necesidades de iluminación y calefacción, así como otro tipo de menesteres, corría de su cuenta ${ }^{5}$.

Si escudriñamos la documentación, sobre todo la notarial o municipal, encontraremos referencias que dan noticias puntuales sobre la existencia de tabernas y hostales en muchas aldeas ${ }^{6}$. La importancia del documento que presentamos sobre los hostales de Villarreal de Huerva radica en su excepcionalidad, pues no hemos encontrado hasta el momento ordenanzas que regulen la explotación de este monopolio para otros lugares de la Comunidad.

Los hostales o diversorios, como la propia denominación que se les da en la documentación indica, no eran únicamente lugares dedicados a la hospedería y provisión de los viajeros, sino también el lugar donde se canalizaba la sociabilidad medieval masculina. En los hostales los viajeros y los convecinos del lugar, ade-

4 RODRIGO ESTEVAN, María Luz, «Viajeros y desplazamientos cotidianos a fines de la Edad Media. Daroca, sus caminos y sus gentes (siglo XV)», Revista de Historia Jerónimo Zurita, 67-68, 1994, p. 112.

5 GARGALLO MOYA, Antonio y SÁNCHEZ USÓN, María José, "Cuentas de un viaje en el siglo XIV: de Teruel a Zaragoza y Barcelona en 1366», Teruel, 71, 1984, pp. 72-75. CARRASCO PÉREZ, Juan y VILLEGAS DÍAZ, Luis Rafael, «Nueva embajada de Navarra a Castilla en 1362: las cuentas del viaje», Historia. Instituciones. Documentos, 8, 1981, p. 106.

6 A los hostales, tabernas, mesones y tablajes de la ciudad de Daroca dedica algunas páginas de su Tesis Doctoral la profesora RODRIGO ESTEVAN, María Luz, Poder y vida cotidiana en una ciudad bajomedieval: Daroca, 1400-1526, (Tesis doctoral s.p.), Universidad de Zaragoza, 1996, pp. 75-78; Sobre la taberna de Monreal del Campo y su tabernero encontramos noticias en un proceso judicial que enfrentó en el año 1421 a Domingo Martín Borrel, habitante de Daroca, contra Alí de Betxí, moro del lugar de Betxí del reino de Valencia, por la pérdida de un fardo de ropa. Archivo Municipal de Daroca (A.M.D.), 17.15.03., Procesos Justicia, 1421; y del hostal de la aldea de Báguena tenemos noticias de los pagos realizados por el concejo a Antolino Pérez, regente de la posada del lugar, por el hospedaje de varios obreros especialistas que trabajaron en las obras realizadas en la iglesia parroquial a comienzos del siglo XV. Véase PARDILLOS MARTÍN, David, Colección de documentos del Archivo Parroquial de Báguena (1363-1505), Documentos para la historia de Daroca y su Comunidad, n. ${ }^{\circ} 4$, Daroca, Centro de Estudios Darocenses, 2007. 
más de comer y descansar, se relacionaban, consumían alcohol y jugaban a juegos de azar, y, en ocasiones, causaban desórdenes y se peleaban?

\section{LAS HOSPEDERÍAS DE VILLARREAL DE HUERVA}

La localización de la aldea de Villarreal en una encrucijada de caminos entre el valle del Huerva y la Sierra del Peco, zona de acceso natural por el Campo de Romanos desde Zaragoza, capital del reino, hacia las ciudades de Teruel y Daroca, puede explicar la existencia de dos hospederías en este pequeño lugar perteneciente en la Edad Media a la Comunidad de aldeas de Daroca ${ }^{8}$.

La aldea percibía una serie de rentas por la explotación de los hostales. En Villarreal de Huerva los oficiales del concejo cedían su explotación cada seis años mediante contratos de arriendo. Como se comprobará seguidamente, existía todo un conjunto de disposiciones, sancionadas por medio de un Privilegio Real dado a la Comunidad de aldeas, tendentes a regular la explotación de este monopolio concejil, tanto en lo referente a su forma de usufructo como en lo referente a su mal uso. Todo ello con vistas a evitar abusos y fraudes, que debían ser bastante frecuentes a pesar de todo.

El 10 de octubre de 1457, los jurados y oficiales de la aldea subscribían, tras haberse pregonado públicamente y subastado al mejor postor, un contrato de arrendamiento en beneficio del concejo del lugar, por el que cedían la explotación de los hostales o posadas de la aldea por 200 sueldos y por tiempo de seis años a Martín de Manyes y Vicente don Sancho, vecinos de Villarreal.

El arriendo se hacía en virtud de un privilegio real que el monarca Alfonso $\mathrm{V}$ había concedido de forma graciosa el 3 de mayo de 1441 a la Comunidad de las

\footnotetext{
7 A este respecto, los Fueros de Aragón recogen disposiciones penales para castigar los delitos de agresión y homicidio cometidos en las tabernas. «Jaime I, Zaragoza, 1247. Si unos hombres fuera del dueño del baño, horno, taberna pública [y] molino y fuera de su familia se hieren o matan allí mismo, el dueño de estos lugares no pueda quejarse por quebrantamiento de la casa ni considerarse deshonrado por esto. Pero quienes se hayan herido en tales sitios, paguen multa según Fuero». «Si un hombre se queja de que otro hombre lo ha golpeado en una taberna pública y el otro lo niega diciendo que él no le golpeó, el que dice que fue golpeado debe probar mediante testigos que lo vieron y estuvieron presentes en la consumación del daño. Si no puede probarlo, que reciba el juramento del adversario, puesto que la taberna pública no tiene torna a batalla». SAVALL y DRONDA, Pascual y PENÉN y DEBESA, Santiago, Fueros, Observancias y Actos de Corte del reino de Aragón. (Edición facsimilar realizada con ocasión del IV centenario de la ejecución de D. Juan de Lanuza, Justicia de Aragón), Tomo III, Zaragoza, El Justicia de Aragón e Ibercaja, 1991, pp. 178 y 267.

8 A mediados del siglo XIII y como consecuencia de la transformación de las estructuras económicas y sociales que vive el Reino de Aragón, nacen las Comunidades de aldeas. La Comunidad de Daroca, la primera en crearse, se configurará mediante la conjunción de varias aldeas, hasta entonces dependientes de la ciudad de Daroca, que se organizarán de manera autónoma, alcanzando elevadas cuotas de autogobierno. Véanse CORRAL LAFUENTE, José Luis, «El origen de las comunidades medievales aragonesas», Aragón en la Edad Media, VI, 1984, pp. 67-94. y CORRAL LAFUENTE, José Luis, La Comunidad de aldeas de Daroca en los siglos XIII y XIV: origen y proceso de consolidación, Zaragoza, Institución Fernando el Católico, 1987, pp. 46-62.
} 
aldeas de Daroca, por el que se permitía el arriendo de este monopolio por espacio de seis años. El precio estipulado era de 200 sueldos repartidos en cuotas anuales de 33 sueldos y 4 dineros, que debían ser pagadas a los jurados de la aldea para provecho y utilidad del lugar, el día 29 de septiembre de cada año, festividad de San Miguel.

Ambas partes se obligaban a cumplir y respetar lo estipulado en el contrato de arriendo, poniendo como fianzas bienes propios susceptibles de ser ejecutados y subastados públicamente al mejor postor en caso de incumplimiento. En el contrato se estipulan, además, una serie de condiciones y penas que, junto con las ordenanzas que regulan el arrendamiento y que se analizan a continuación, las dos partes contratantes prometían observar.

\section{CONDICIONES DE ARRENDAMIENTO}

Las cláusulas de los contratos fijaban las condiciones económicas. Como ya se ha dicho, en Villarreal los arrendadores debían pagar 200 sueldos por la concesión de su explotación durante seis años y se les exigía el pago fraccionado de la cantidad mediante abonos anuales de 33 sueldos y 4 dineros. Es claro que, como se desprende del documento, el arrendamiento concejil de los hostales era para «...para provecho e utilidat del dito lugar...»". De tal modo que el concejo se aseguraba:

a) el control de los precios, que quedaban así fijados;

b) la obtención de unos ingresos anuales en concepto de arriendo y en concepto de penas por la transgresión de las ordenanzas;

c) y, lo más importante, el control municipal del monopolio.

El arriendo estaba condicionado a una serie de obligaciones que los contratantes debían aceptar y cumplir. Entre ellas, la de vender durante el periodo del contrato el cuartal de la cebada tal y como era costumbre y como hacían los hostaleros de los lugares comarcanos.

De la misma manera, el concejo establece el control sobre los precios cobrados por el lecho y por la comida servida al viajero y ordenan a los posaderos que se sujeten a lo acostumbrado, a fin de evitar fraudes y abusos sobre los transeúntes. A pesar de ello, algunos autores han apuntado la escasa incidencia que dentro de los gastos generales de un viaje tenían los dedicados al alojamiento ${ }^{10}$.

Una de las provisiones hace referencia a la prohibición que tenían los posaderos de vender pan a los viajeros en los hostales del lugar. El concejo mostraba,

\footnotetext{
9 Archivo Histórico de Protocolos Notariales de Zaragoza (A.H.P.Z.), Juan Ram, 1457, f. 241 v.

10 CARRASCO PÉREZ, Juan y VILLEGAS DÍAZ, Luis Rafael, Op. cit., p. 106.
} 
una vez más, su interés por controlar la actividad de los hostales, ya que la venta de pan era un derecho que se arrendaba anualmente. Cada fraude estaba penado con 10 sueldos jaqueses que habrían de dividirse en dos partes, una para los jurados y oficiales del lugar y otra para el erario del concejo. Se establecía como excepción la llegada de viajeros a la hospedería de noche ya cerrada; en este caso, para facilitar el aprovisionamiento de los mismos, se daba a los hostaleros la merced de vender pan a los transeúntes sin pena alguna por ello.

A estas cláusulas que condicionaban el arrendamiento se sumaban una serie de ordenanzas. Reunido el concejo de Villarreal de Huerva el día 11 de octubre de 1457 en el pórtico de la iglesia de San Miguel, donde era costumbre en el lugar formar concejo, y después de confirmar el arrendamiento realizado a los dos vecinos de la localidad el día anterior, fueron redactados y testificados por el notario Juan Ram unos estatutos compuestos de ocho capítulos que regulaban la explotación de los hostales.

1) Con el objetivo de asegurarse el control sobre el monopolio, el concejo prohíbe que, durante los seis años de duración del arrendamiento, otras personas tengan posadas en la aldea salvo los dos vecinos contratantes o sus sucesores naturales. Todo ello bajo pena de 10 sueldos jaqueses que habrían de dividirse, esta vez, en tres partes, una para los jurados y oficiales del lugar, otra para las arcas del concejo y otra para los arrendadores de los hostales. Esta disposición hace pensar en la existencia de un negocio encubierto a través del cual algunos vecinos aprovechaban el ir y venir de transeúntes para ofrecerles habitaciones particulares, probablemente a precios más económicos o con mejor servicio, buscando obtener un dinero extra que complementase su economía familiar. Contra esta forma de negocio particular en los lugares donde había posadas, como es el caso de Villarreal de Huerva, luchan las autoridades concejiles estableciendo una serie de penas pecuniarias para evitar el fraude y para dar protección legal al monopolio, castigando a los vecinos que acogieran clandestinamente a viajeros en sus casas.

La disposición hace una excepción con los familiares más cercanos permitiendo a los vecinos de Villarreal alojar en sus casas a padres, hijos, suegros, hermanos, yernos y nueras. También se hacían excepciones en caso de que la reunión de la plega ${ }^{11}$ o asamblea general de la Comunidad de Daroca se realizase en dicho lugar o, bien, si por la aldea pasasen y se alojasen, además de los monarcas $^{12}$, oficiales del reino o personas notables que viajaban con séquitos importan-

11 Las plegas no tenían un lugar fijo para su celebración. Iban rotando por las aldeas de la Comunidad, aunque generalmente se buscaban las más céntricas, las mejor comunicadas y las de mayor entidad de población. De ahí que los lugares más frecuentes para la celebración de las plegas fueran Anento, Romanos, Mainar, Ferreruela, Torrecilla del Rebollar, Villarreal, Badules y las grandes aldeas como Burbáguena, Báguena, Azuara y Cariñena. CORRAL LAFUENTE, José Luis, La Comunidad de aldeas de Daroca..., p. 83.

12 La foralidad aragonesa no hace mención expresa al modo en que debían hospedarse los monarcas en sus desplazamientos, sin embargo, en el vecino reino de Navarra, la regulación del hospedaje de los monarcas cuando se hallaban en lugares de señorío estaba determinada por los Fueros de Navarra. 
tes. En esos casos, se permitía el alojamiento en las casas de otros vecinos de la aldea. Además de por cuestiones de espacio, las malas condiciones y la reputación de estos establecimientos ${ }^{13}$ serían seguramente las causas que llevarían al concejo a determinar que cuando personas importantes visitasen o pasasen por la localidad y por su condición personal «no fuesse decent a alguno dellos posar e alogarse en vuestros hostales ${ }^{14}$ tuvieran los oficiales del concejo la potestad de poderlos alojar en las casas de otros vecinos que estuviesen mejor acondicionadas.

2) El siguiente capítulo se encuentra barreado en el texto original, por lo que, aunque redactado, entendemos que no se pondría en vigencia. En él se disponía el que cualquier persona, independientemente de su condición social o creencia religiosa, que acudiera a Villarreal de Huerva habría de alojarse únicamente en las hospederías contratantes, bajo pena de 10 sueldos jaqueses que habrían de dividirse de la misma manera que se establecía en el capítulo anterior.

3) Se otorgaba a los jurados y a sus lugartenientes, en caso de ausencia de sus principales, y a los corredores públicos del lugar, en caso de ser designados por los jurados, la potestad de ejecutar las penas consecuencia del quebrantamiento de los estatutos. En caso de tener que proceder al embargo de bienes muebles para poder cobrar las multas establecidas se les dada también la autoridad para poderlos subastar públicamente.

4) Caso de no encontrarse bienes muebles suficientes en las casas de los condenados con los que satisfacer las penas a las que habían sido castigados, los jurados procederían de oficio al apresamiento del reo, que sería colocado en un cepo hasta que solventase su deuda.

5) Para facilitarles el ejercicio de su trabajo y para protegerles de posibles agravios en su contra, los jurados y los corredores públicos a los que se les encargaba la ejecución de las penas, en caso de serles hecha resistencia o en caso de ser injuriados, amenazados o vituperados por los condenados o por sus familiares o cercanos, podían dar cuenta de estas acciones al Justicia de la ciudad de Daroca en el plazo posterior al agravio de cuatro días. En tales circunstancias, los jurados o corredores podrían estimar la ofensa en una cuantía máxima de 50 sueldos, o en la cantidad inferior que estimaran.

Sería necesario el testimonio de dos testigos para que el Justicia de Daroca o su lugarteniente tuviera a bien la relación de los jurados o corredores. Dado el caso que las injurias y amenazas hubieran sido realizadas verbalmente, sin testigos que las pudiesen atestiguar, los jurados o corredores serían creídos en virtud del juramento de fidelidad y honor al cargo que prometieron al alcanzar su oficio. En tales circunstancias, de nuevo, los jurados o corredores podrían estimar la ofensa en

UTRILLA UTRILLA, Juan Fernando, El Fuero General de Navarra, Volumen I, Pamplona, Fundación Diario de Navarra, 2003, pp. 209-210.

${ }_{13}$ MENÉNDEZ PIDAL, Gonzalo, Los caminos en la historia de España, Madrid, Ediciones Cultura Hispánica, 1951, p. 74.

${ }_{14}$ A.H.P.Z., Juan Ram, 1457, f. 242v. 
cuantía máxima de 50 sueldos, o en la cantidad inferior que estimaran a cargo de su conciencia y alma. En cualquier caso, para la ejecución de estos 50 sueldos el Justicia de la ciudad procedería a mandar por escrito la orden de su cobro tanto al procesado como a los jurados del lugar o a los nuncios de su corte ${ }^{15}$ para que éstos, posteriormente, procedieran a su venta pública.

6) En el caso de que los procesados presentaran firmas de derecho ${ }^{16} \mathrm{o}$ agravios contra las acciones interpuestas contra ellos y, tras petición expresa de los jurados, se negaran a retirarlas, se estipulaba que se les impusiese una sanción de 20 florines de oro que habrían de engrosar las arcas reales y que deberían ser requeridos por el procurador fiscal del monarca. Además, independientemente de las firmas de derecho presentadas, se da poder a los jurados para que puedan proceder a la ejecución de las sanciones comentadas en los apartados anteriores.

7) Para evitar posibles problemas a los jurados o corredores se ordena que las firmas de derecho presentadas contra ellos por el ejercicio de su cometido, ejecutando sanciones o encarcelando a los inculpados remisos a pagarlas, no tengan valor. Asimismo, el manifestante de las mismas incurriría en pena de 50 florines de oro, que engrosarían también el fisco real, a los que habría que sumar el pago de todas las expensas y daños producidos a los jurados o corredores. De no encontrarse bienes muebles suficientes en las casas de los condenados con los que compensar a los jurados o corredores agraviados y con los que satisfacer los 50 florines ya citados, los jurados podrían proceder de oficio al apresamiento del reo que sería colocado prisionero en un cepo hasta que solventase su deuda.

8) En el último punto se recoge la renuncia expresa a cualquier fuero, derecho, privilegio o firma de agravio que pudiese contravenir lo establecido por el concejo, es decir se prescindía de cualquier resquicio legal al que pudieran acogerse los vecinos del lugar para transgredir las ordenanzas y salir indemnes de su quebranto.

Estos estatutos, a través de los cuales el concejo de Villarreal de Huerva controló la explotación del monopolio, sirvieron no sólo para regular las obligaciones de los hostaleros respecto al uso de la concesión sino también para regular la obtención de unos ingresos económicos. El concejo se aseguraba la obtención de beneficios económicos tanto ordinarios, derivados del contrato de arrendamiento, como extraordinarios, estableciendo penas pecuniarias tanto a los arrendadores, por el mal uso del monopolio, como a los vecinos del lugar, por el quebrantamiento de lo dispuesto en los estatutos.

15 Los nuncios o sayones formaban parte de los cuerpos auxiliares de la corte del Justicia de Daroca y se ocupaban fundamentalmente de misiones ejecutivas y de apoyo, tales como las citaciones de las partes litigantes, los encarcelamientos, los procesos de embargo, las subastas de los bienes confiscados, etc. PARDILLOS MARTÍN, David, «Un pleito en torno a la explotación de las tierras de pastos en la Comunidad de aldeas de Daroca (Año 1500)», Aragón en la Edad Media, XIX, 2006, p. 438.

16 Mediante la «firma de derecho», podía el Justicia de Aragón detener la acción de cualquier tribunal aragonés, a la vez que garantizaba al acusado la protección de cualquier clase de presión o agresión hasta que él ultimase el juicio, siempre y cuando se pagara una fianza, que es lo que se llama precisamente firma de derecho. 


\section{APÉNDICE DOCUMENTAL}

1

1457.10.10. Villarreal de Huerva (Zaragoza)

El concejo de Villarreal de Huerva arrienda por 200 sueldos jaqueses y por tiempo de seis años el uso de los hostales de la aldea a Martín de Manyes y Vicente don Sancho, vecinos del lugar.

- Archivo Histórico de Protocolos Notariales de Zaragoza, Juan Ram, 1457, ff. 241r.-244v.

Tributacion de los hostales de Villareal por seys anyos.

Sepan todos como nos Jayme Martin et Miguel d'Arinyo, vezinos et jurados del lugar de Villareal, lugar qui es de la Comunidat de las aldeas de la ciudat de Darocha, Nicholas de la Foz, menor, et Miguel Paricio e Nicholas Ruvio, menor, vezinos e officiales del dito lugar en el present e infrascripto anyo, como officiales sobreditos por utilidat del concexo del dito lugar vendemos siquiere arendamos a vosotros Martin de Manyes, abssent, e Vicent don Sancho, present, vezinos del dito lugar de Villareal qui present soys, que podades tener le tengades/ diversorios o ostales en el dito lugar para todos los idores e venidores al dito lugar et del dito lugar. Et aquesto mediant Andres de las Eras, vezino e corredor publico del dito lugar, alli present, el qual fizo fiel relacion a mi Johan Ram, notario, Ipresentes los/ testimonios dius nombrados, el de mandamiento de los ditos officiales e de los officiales del anyo agora passado haver pregonado el tener de los hostales o diversorios en el dito lugar por diversos dias e horas et por las plaças e carreras acostumbradas del dito lugar qui queria arrendar el tener de aquellos e por tiempo de seys anyo continuos. Et no havia trobado qui tanto ni mas precio huviesse ni haya preferido en aquellos que los ditos Martin de Manyes et Vicent don Sancho qui preffirieron por [tachado: aquellos] ellos et por el tener de aquellos et por el tiempo sobredito de seys anyos dozientos sueldos jaqueses. E aquesto Inos ditos jurados et officiales/ fazemos por lvigor de hun/ privilegio a la dita Comunidat e cada un lugar de la dita Comunidat, por la gracia magestat del senyor rey atorgado patent, ubierto, [tachado: sellado] en cera vermella con siello Ide su real celsitud sellado/ pendient en veta de seda de colores de amariello e vermexo que dado fue in felicibus castris, prope pontem Arreguini, die tercio madii anno a Nativitate Domini $\mathrm{M}^{\circ} \mathrm{CCCC}^{\circ}$ quadragesimo primo et alios. E laquesto/ por tiempo de los ditos seys anyos primeros vinientes continuos e por mediament subseguideros començaderos a correr del present e infrascripto dia de hoy adelant contaderos e por dozientos sueldos jaqueses por todos los ditos seys anyos pagaderos por vosotros e los vuestros a los jurados qui son o por tiempo seran del dito lugar para provecho e utilidat del dito lugar [tachado: cada un anyo] el dia e fiesta de senyor Sant Miguel de setiembre que es partida en cada un anyo la dita quantia trenta tres sueldos e quatro dineros jaqueses Icada un anyo/. Los quales trenta tres sueldos e quatro dineros jaqueses paguedes cada un anyo a los jurados qui son o por tiempo seran del dito lugar el dia e fiesta de Sant Miguel de setiembre [tachado: por los] durant el tiempo de los ditos seys anyos.

La qual vendicion siquiere arrendacion vos fazemos con las condiciones siguientes:

1) Que vosotros vendades el quartal de la cevada como en los lugares comarquanos continuament en todos los tiempos de los ditos seys anyos los hostaleros de los lugares comarquanos la vendian et ad aquel respecto cada almut Ivendades/. 
2) E [tachado: assi] de lecho et de tabla en la manera acostumbrada por aquestas cosas exhagades e no mas.

3) Et es assi que otra persona ni personas no sean lesadas ni puedan tener diversorios ni hostales en el dito lugar para acoxer los idores et venidores ad aquel et en aquel durant el dito tiempo de los ditos seys anyos, sino vosotros dos o successores vuestros durant aqueste tiempo de los ditos seys anyos dius pena al contrafazient o contrafazientes por cada una vegada de diez sueldos jaqueses dividideros en tres partes, la una para los jurados e officiales del dito lugar qui son o seran, la otra para el concexo del dito lugar que sea para utilidades de aquel et la otra para vosotros ditos arendadores. Si ya no es que las tales persona o personas hayan acoxido padre o madre, o fixo o fixa, o yerno o nuera, o suegro o suegra, o hermano o hermana que de fuera del dito lugar haya venido ad aquel o en caso que plega general o ajust de parlament de officiales e prohombres de la dita Comunidat se tuviesse en el dito lugar. O en passatge del senyor rey o de su lugartenient o de la senyora reyna o del governador o del rigient el officio de la governacion o de algun grant official, prelado o noble, o varon, o senyor que ellos ni sus companyas no pudiassen alogarse en vuestros hostales ni fuesse decent a alguno dellos posar e alogarse en vuestros hostales. Que en qualquiere de aquestos casos los officiales qui son por tiempo seran del dito lugar puedan a su arbitrio colloquar e alogar en las casas de los otros vezinos del dito lugar los tales senyores o personas a arbitrio dellos sines de pena alguna a los ditos officiales ni a los acoxientes aquellos.

4) $E$ tanbien vos fazemos la present arrendacion con condicion que no podades vender pan a los tales idores e venidores dius la dita pena encorredera por cada una vegada e divididera en dos partes, la una para los jurados e officiales del dito lugar qui son o por tiempo seran e la otra para el util e provecho del dito lugar, levadores de cada uno de vos por cada una vegada, sino es en caso de seyer grant noche que lo podays fazer sin pena alguna. Et encara [tachado: lo] podays fazer segunt la costumbre del dito lugar en los comercios de los vivres e no en otra manera.

E con aquesto teniendo, cumpliendo et obsservando todas e cada unas cosas sobreditas como dito es, prometemos, convenimos e nos obligamos durant el dito tiempo de los ditos seys anyos no tirar vos el tener de los ditos hostales o diversorios ante mantener vos en pasciffica possession de aquellos durant el dito tiempo dius obligacion de todos los bienes del dito concexo del dito lugar, mobles e sedientes, havidos e por haver, en todo lugar.

E yo dito Vicent don Sancho qui presente so por mi et por el dito Martin de Manyes ya sea abssent de vos ditos jurados e officiales los ditos hostales o diversorios e el tener de aquellos por el dito tiempo de los ditos seys anyos et por los ditos dozientos sueldos jaqueses por los ditos seys anyos, pagaderos cada un anyo [tachado: al dia] trenta tres sueldos quatro dineros jaqueses el dia et fiesta de senyor Sant Miguel de setiembre, et con las ditas condiciones, penas et en la forma sobredita, las quales quiero aqui haver et he por repetidas et specifficadas et de palavra a palavra largament declaradas, tomo siquiere recibo. E prometo, convengo et me obligo servir e tener por el dito Martin de Manyes e por mi durant el dito tiempo los ditos diversorios o hostales et fazer e servar todas e cada unas cosas sobreditas e lo contrario no fazer ni permeter fazer por mi ni otri por mi ni por el dito Martin de Manyes ni otri por el. A lo qual tener e complir obligo vos ende todos mis bienes mobles e sedientes, havidos e por haver, en todo lugar. E prometo, convengo e me obligo en el tiempo de la execucion fazedera por qualquiere de las sobreditas cosas haver, dar e assignar bienes mios mobles, proprios, quitos e desembargados a complimiento de todas e cada unas cosas sobreditas, los quales quiero quende podades fazer sacar e vender luego a uso e costumbre 
de cort e de alfarda segunt que uso e costumbre es en Aragon de vender penyoras de alfarda fechas tansolament de aquellas tres almonedas por tres dias. Et renuncio a dia de acuerdo e diez dias pora cartas cerquar. Et prometo, convengo e me obligo por qualquiere de las sobreditas cosas fazer vos complimiento de derecho e de justicia antel senyor Governador \General/ rigient el officio de la Governacion, Justicia de Aragon, Justicia de la dita ciudat, jurados del dito lugar, antel qual o los quales mas por qualquiere de las sobreditas cosas convenido sere o el dito Martin de Manyes convenido sera, a la iurediccion, cohercion e compulsa del qual o de los quales agora por la hora e viceversa me iusmeto, dando vos permission que sobre qualquiere de la sosbreditas cosas podades variar un judicio o muytos e de una accion en otra sines de reffussion de expensas algunas. E quiero que los jurados que son o por tiempo seran del dito lugar de por si puedan executar mis bienes por las sobreditas quantias e penas e aquellos vender como en fechos e bienes de alfarda toda solempnidat de fuero e de derecho apart posada, a la qual expressament e de cierta sciencia renuncio.

Feyto fue esto en el lugar de Villareal a diez dias Idel mes/ de octobre anno a Nativitate Domini millesimo $\mathrm{CCCC}^{\circ} \mathrm{L}^{\circ}$ septimo. Presentes testimonios son de aquesto Nicholas Ruvio, maior de dias, e Yust Sancho, vezinos del lugar de Villareal.

2

\subsubsection{Villarreal de Huerva (Zaragoza)}

Martín de Manyes, vecino de Villarreal, ausente el día anterior cuando se acordó el arriendo de los hostales a él y a Vicente don Sancho, acepta y ratifica el contrato de arrendamiento.

- Archivo Histórico de Protocolos Notariales de Zaragoza, Juan Ram, 1457, ff. 244v.-245r.

Apres de aquesto, dia es a saber que se contava a onze dias del dito mes de octobre del dito anyo en el dito lugar, yo dito Martin de Manyes [tachado: accepto], qui present so, accepto la dita e present vendicion siquiere arendacion de los ditos diversorios o hostales al dito [tachado: Martin de Manyes] IVicent don Sancho/, present, e a mi abssent con las ditas condiciones, penas, tiempos, quantias, obligaciones, renunciaciones, submissiones e variaciones et permissos, accepto e tomo e loho e aprovo lcon el e sin el/. Et assi me obligo como si mi present se huviesse fecho en la manera que al dito [tachado: Martin de Manyes] IVicent don Sancho/. Las quales he por leydas, repetidas, specifficadas e de paraula a paraula largament declaradas, assi las tomo, prometo e me obligo. Renuncio e me iusmeto e do permisso segunt de suso mas largament es recitado.

Presentes testimonios son de aquesto mossen Anthon de Umanyas, rigient la cura del dito lugar de Villareal le habitante en aquel/ e don Nicholas Ruvio, maior, [tachado: vezino del] vezino del dito lugar. 


\subsubsection{Villarreal de Huerva (Zaragoza)}

Estatutos que regulan el arrendamiento de los hostales de Villarreal de Huerva establecidos por el concejo del lugar.

- Archivo Histórico de Protocolos Notariales de Zaragoza, Juan Ram, 1457, ff. 245r.-251r.

Statutos fechos por el concexo del lugar de Villareal.

Sepan todos que clamado, plegado e ajustado el concexo de los jurados, officiales e hombres del lugar de Villareal a son de campana segunt que Andres de las Eras, vezino e corredor publico del dito lugar, alli present fizo fe e relacion a mi Johan Ram, notario, presentes los testimonios dius nombrados el de mandamiento de los jurados e officiales infrascriptos el haver clamado el concexo de los jurados, officiales e hombres del dito lugar a son de campana lel present e infrascripto dia/. E plegado e ajustado el concexo del dito lugar en el portegado de la iglesia de senyor Sant Miguel del dito lugar let fuera la dita iglesia/ do otras vegadas por tales e semblantes actos e cosas se es acostumbrado plegar e ajustarse el dito concexo del dito lugar. En el qual fuemos e interviniemos los siguientes: nos Jayme Martin e Miguel d'Arinyo, vezinos e jurados del dito lugar, Nicholas de la Foz, menor, Miguel Paricio e Nicholas Ruvio, menor, vezinos e officiales del dito lugar en el present anyo, Johan Calvo, Johan Martin, Vicent don Sancho, Martin de Manyes, Anthon d'Almaçan, Miguel Lopez, Per Arinyo, Miguel Lazaro e Yust Sancho, vezinos del dito lugar, et de si todo el concexo del dito lugar de los vezinos e habitantes en aquel a concexo clamados, plegados e ajustados concexantes, concexo e universidat fazientes e representantes, todos concordes e alguno de nos no discrepant ni contradizient havemos por rata e firme la vendicion siquiere arendacion de los hostales o diversorios fecha a Martin de Manyes e Vicent don Sancho, vezinos del dito lugar, por el tiempo de los seys anyos e por los dozientos sueldos et con las condiciones et en la manera que fecha es, que fecha fue en el lugar de Villareal a diez dias de octobre del anyo e por el notario infrascripto testificada.

E con aquesto [tachado: el dito] Inos/ concexo e nos desuso nombrados en nombre e voz del dito concexo de los officiales e singulares de aquel lpor los/ qui agora somos e por tiempo seran de aquel lpresentes, absentes et advenideros del dito lugar/ statuymos e ordenamos:

1) Que persona alguna de qualquiere ley, stado o condicion sean no sea osada ni pueda tener diversorios o hostales en el dito lugar para acoxer los idores e venidores de aquel e ad aquel en tiempo alguno sino los qui son o seran arendadores puestos por los jurados e officiales qui son o por tiempo seran del dito lugar dius pena al contrafazient o contrafazientes por cada una vegada de diez sueldos jaqueses dividideros en tres partes; la una para los jurados e officiales qui son o por tiempo seran del dito lugar, la otra para el concexo del dito lugar que sea pora utilidades de aquel et la otra pora los arrendadores qui son o por tiempo seran de los diversorios o hostales del dito lugar si ya no es que las tales persona o personas hayan acoxido padre o madre, o fixo o fixa, o yerno o nuera, o suegro o suegra, o hermano o hermana, que de fuera del dito lugar haya venido ad aquel, o en caso que plega general o ajust de parlament de officiales e prohombres de la dita Comunidat se tuviesse en el dito lugar, o de passage del senyor rey o de su lugartenient o de la senyora reyna o del governador 
o del rigient el officio de la governacion o de algun grant official, prelado o noble o varon o senyor que ellos ni sus companyas no pudiessen alogarse en los hostales ni fuesse decent a alguno dellos posar e alogarse en los hostales. Que en qualquiere de aquestos casos los officiales qui lagora/ son o por tiempo seran del dito lugar puedan a su arbitrio collocar e alogar en las casas de los otros vezinos del dito lugar los tales senyores o personas a arbitrio dellos sin pena alguna a los ditos officiales ni a los acoxientes aquellos.

2) [Al margen: Vacat este capitol] [Barreado todo el párrafo] Item, statuymos e ordenamos que persona alguna de qualquiere stado o condicion sea que verna al dito lugar no pueda en tiempo alguno posar en hostales algunos sino en los hostales de los arendadores qui son o por tiempo seran de los jurados e officiales del dito lugar dius pena al tal o tales contrafazient o contrafazientes por cada una vegada de diez sueldos jaqueses levaderos et dividideros pro ut supra.

3) Item, statuymos e ordenamos que en la execucion de qualquiere de las ditas penas e de cada una dellas caso que acahesceran et por cada una vegada, los jurado o jurados del dito lugar qui son o por tiempo seran o sus lugarestenientes pueda e puedan aquella o aquellas por si fazer, exhigir, executar e levar, o mandar fazer, exhigir, executar, elevar o por corredor o corredores dados o que crearan de aqui adelant. E aquesto qualquiere dia e hora et en qualquiere tiempo, feriado o non feriado, et las penyoras de aquella execucion vender e trauçar o mandar vender e trauçar luego o quando querra e por el precio que su consciencia arbitrara sines de solempnidat alguna de fuero ni de derecho no servada, no clamado ni scitado el que executado sera sino al modo de alfarda o como entendra e le plazera sines de pena e calonia alguna.

4) Item, statuymos e ordenamos que el jurado o los jurados qui son o por tiempo seran del dito lugar que mandaran fazer o excutar o executaran o faran execucion por qualquiere de las ditas penas no trobaran bienes mobles expeditos bastantes et sin empacho alguno al complimiento de qualquiere de las ditas penas, queremos que los tal o tales jurado o jurados pueda o puedan ex officio tomar preso o presos [tachado: los tal o tales] las persona o personas que en las ditas penas o alguna dellas incidido havran e las tales persona o personas puedan poner et meter en el cepo. Et tener et tengan aquellas tanto tiempo fasta las ditas pena o penas sean realment pagadas. $E$ aquesto puedan fazer et fagan por tantas vegadas quantas en aquella o aquellas las tales persona o personas inscidido havran. E aquesto qualquiere dia et en qualquiere tiempo et en qualquiere hora, feriado o no feriado.

5) Item, statuymos e ordenamos que qualquiere jurado o jurados [tachado: del] qui son o por tiempo seran del dito lugar o los corredor o corredores que de mandamiento de alguno de los ditos jurados qualquiere de las ditas execuciones fara o fecho havra, e por el tal penyorado o executado o capcionado lo que se penyorara, o executara o capcionara/ o por sus muxeres, fixos o fixas o messatges o companyas se les fara resistencia o se les dira vituperio o injuria o los menazara, [tachado: que] que los tal jurado o jurados o corredor o corredores apres la dita injuria, resistencia, vituperio o menazas pueda fazer relacion ante el Justicia de la ciudat de Daroqua qui es o por tiempo sera o ante su lugartenient dentro quatro dias continuos e inmediadament subseguideros apres que la tal resistencia fecha sera, vituperio o injuria o menazas, dicho o fecho le havran. E el tal jurado o jurados, o corredor o corredores, pueda e puedan stimar la dita injuria, vituperio o menaza fines en quantia de cinquanta sueldos o de alli ayuso lo que querra. Et si resistencia le sera fecha rogar al justicia o su lugartenient lo haya por notorio segunt la quantidat et stima de la resistencia. El qual notorio segunt el delicto de la resistencia se pueda larbitrar e/ ampliar segunt la resistencia fecha sera. 
Et en la relacion de la tal resistencia que fara lel jurado o corredor/ al dito Justicia o su lugartenient no pueda seyer creydo el tal jurado o corredor sino con dos testimonios al menos. E si mas ni havra a los hide querra con aquellos o si hide havra notario e testimonios que se ste al acto que el notario testifficara. E si sera vituperio o injuria o menaza fecha de palabra se haya a star et se ste a sola e simple relacion de tal jurado o del corredor por el jurament que cada uno presto al principio de su officio et sea creydo sin testimonios et se pueda stimar la dita injuria o vituperio o menaza pues manualment no sea fecha en los ditos cinquenta sueldos o de alli ayuso lo que el tal jurado o corredor declarara a cargo de su consciencia e anima. E que para [tachado: execu] acusacion de la resistencia en sus caso o vituperio o injuria o menaza pues manualment no sea fecha en el suyo el tal jurado o jurados, o corredor o corredores, ara sian officiales ara fuera del officio sean siempre part a poderlas acusar, exhigir e demandar, no obstant disposicion qualquiere de fuero o de derecho en contrario de qualquiere de aquestas cosas disponient, a la qual expressament e por special pacto renunciamos. E que por la execucion de la pena de los ditos cinquanta sueldos o de alli ayuso el dito Justicia o su lugartenient puedan mandar executar por sus letras Imediant/ el jurado del dito lugar o por los nuncios de la cort del dito Justicia la los tal o tales e se faga/ breument, sumaria e de plano como en fecho de alfardas solempnidat alguna no servada a la qual expressamente renunciamos.

6) Item, statuymos e ordenamos que si por la execucion o capcion de qualquiere de las sobreditas cosas e pora empacho de las cosas por nosotros de suso ordenadas lo de qualquiere dellas/ se presentara firma Ide derecho/, de greuge fecho o fazedor, por qualquiere vezino o havitador del dito lugar si requerido de la tal presentacion cara a cara lpor los jurados qui son o por tiempo seran del dito lugar/ luego de aquella no desistira et no se partira e la execucion de qualquiere de las sobreditas penas empachara como lo tal empachar venga contra el mandamiento e privilegio de la majestat del senyor rey e en menosprecio de su real celsitud que el tal presentant o empachant las tal o tales pena o penas o capcion o capciones ipso facto e foro encorra en pena de vint florines aplicaderos a los cofres del senyor rey lpor cada una vegada/ e que el procurador fescal del senyor rey los pueda executar o fazer executar a los tal o tales, las tal o tales firmas de derecho presentes et las ditas penas e capciones empachantes e sia part [tachado: para poder] el dito procurador fiscal a poderlos levar e exhigir. E no obstant las ditas firma o firmas de derecho los ditos jurados e/o corredor o corredores puedan las ditas penas e capciones fazer executar e a devido effecto trayer sines de pena e calonia alguna. A las quales firma o firmas de derecho assi obtenidas como obtenederas por special pacto renunciamos et por renunciadas queremos seyer havidas assi como si por pronunciacion del lugartenient de Justicia de Aragon repellidas fuessen. $\backslash E$ que el lugartenient de Justicia de Aragon a sola hostension de la present repellezca qualquiere firma de drecho obtenida o por obtener por qualquiere singulares vezino del dito lugar obtenida o que se obtendra quanto toqua a las cosas contenidas en las presentes ordenaciones e cada una dellas/.

7) Item, statuymos e ordenamos que si el jurado o jurados o los corredor o corredores qui son o por tiempo seran del dito lugar por haver fecho o executado qualquiere de las ditas penas o capciones assi ante de haverles seydo presentada firma de derecho, de greuge fecho o fazedor, como apres de la presentacion de la dita firma de derecho sera o seran los tales jurado o jurados e corredor o corredores acusados o se acusaran ante el senyor rey o su lugartenient, Governador General portant vezes de aquel, Justicia de Aragon o sus lugarestenientes o comissarios algunos o ante qualquiere dellos por qui las ditas firma o firmas de derecho [tachado: presentadas] obtunidas seran o por sus herederos e successores, que- 
remos e ordenamos que el tal acusant incida en pena de cinquanta florines de oro lpor cada una vegada/ aplicaderos a los coffres del senyor rey elevadores et exhigideros por el dito procurador fiscal en la forma e manera e sin solempnidat alguna que de part de suso es declarado. E ultra de aquesto pague al jurado o corredor que scitado o acusado havra e la acusacion fara todas las expensas e danyos que el tal jurado o corredor sustenido havra, de las quales expensas e danyos el tal jurado o corredor sea por su simple palavra crehido et en aquellas expensas e danyos el de por si su jurado o corredor sera o el jurado del dito lugar qui sera por su simple requesta lo creha et pueda executarla, execute los bienes mobles del tal acusant e aquellos venda sumariament en la forma e manera que los ditos diez sueldos de pena executar e vender se pueden. E si no terna el tal acusant bienes bastantes a la execucion o sus bienes havra alienado a fin que realment no pague las ditas expensas e danyos, que en qualquiere de aquestos casos pueda seyer proceydo e se proceda por el dito citado o acusado o por el dito jurado a capcion de la persona de aquel Ipresentant la firma e acussant/ e aquel tenga e pueda tener preso en el cepo tanto e tan largament fasta que las ditas expensas e danyos e pena de los ditos cinquanta florines realment haya pagado.

8) Item, statuymos e ordenamos e por special pacto renunciamos todos e qualesquiere fueros, derechos, privilegios, firmas de greuges fechos o fazederos, obtenidas e por obtener en contrario de qualquiere de las sobreditas cosas vinientes e qualquiere de las sobreditas cosas empachantes, assi como si por pronunciacion del lugartenient de Justicia de Aragon fechas e repellidas fuessen.

[Tachado: Presentes testimonios son de las sobreditas cosas mossen Anthon de Umanyas, rigient la cura del dito lugar de Villareal e habitante en aquel, et don Nicholas Ruvio, maior de dias, vezino del dito lugar.]

Feyto fue esto en el lugar de Villareal a onze dias de el mes de octobre anno a Nativitate Domini $\mathrm{M}^{\circ} \mathrm{CCCC}^{\circ} \mathrm{L}^{\circ}$ septimo. Presentes testimonios son de [tachado: aquesto] Vas sobreditas cosas/ mossen Anthon de Umanyas, rigient la cura del dito lugar de Villareal e habitante en aquel, e don Nicholas Ruvio, maior de dias, vezino del dito lugar.

\section{BIBLIOGRAFÍA}

CARRASCO PÉREZ, Juan y VILLEGAS DÍAZ, Luis Rafael (1981), «Nueva embajada de Navarra a Castilla en 1362: las cuentas del viaje», Historia. Instituciones. Documentos, 8, pp. 85-149.

CORRAL LAFUENTE, José Luis (1984), «El origen de las comunidades medievales aragonesas», Aragón en la Edad Media, VI, pp. 67-94.

- (1987), La Comunidad de aldeas de Daroca en los siglos XIII y XIV: origen y proceso de consolidación, Zaragoza, Institución Fernando el Católico.

GARGALLO MOYA, Antonio y SÁNCHEZ USÓN, María José (1984), "Cuentas de un viaje en el siglo XIV: de Teruel a Zaragoza y Barcelona en 1366», Teruel, 71, pp. 47-136.

MARTÍNEZ GARCÍA, Luis (2000), «La hospitalidad y el hospedaje en el Camino de Santiago», en El Camino de Santiago y la sociedad medieval, Logroño, Instituto de Estudios Riojanos, pp. 97-110.

MENÉNDEZ PIDAL, Gonzalo (1951), Los caminos en la historia de España, Madrid, Ediciones Cultura Hispánica.

PARDILLOS MARTÍN, David (2006), «Un pleito en torno a la explotación de las tierras de pastos en la Comunidad de aldeas de Daroca (Año 1500)", Aragón en la Edad Media, XIX, pp. 433-442.

- (2007), Colección de documentos del Archivo Parroquial de Báguena (1363-1505), Documentos para la historia de Daroca y su Comunidad, n. ${ }^{\circ}$ 4, Daroca, Centro de Estudios Darocenses.

RODRIGO ESTEVAN, María Luz (1994), «Viajeros y desplazamientos cotidianos a fines de la Edad Media. Daroca, sus caminos y sus gentes (siglo XV)», Revista de Historia Jerónimo Zurita, 67-68, pp. 103-137. 
- (1996), Poder y vida cotidiana en una ciudad bajomedieval: Daroca, 1400-1526, (Tesis doctoral s.p.), Universidad de Zaragoza.

SAVALL y DRONDA, Pascual y PENÉN y DEBESA, Santiago (1991), Fueros, Observancias y Actos de Corte del reino de Aragón. (Edición facsimilar realizada con ocasión del IV centenario de la ejecución de D. Juan de Lanuza, Justicia de Aragón), Tomo III, Zaragoza, El Justicia de Aragón e Ibercaja.

UBIETO ARTETA, Antonio (1984), Historia de Aragón. Los pueblos y los despoblados, Tomo III, Zaragoza, Anubar Ediciones.

UTRILLA UTRILLA, Juan Fernando (2003), El Fuero General de Navarra, Volumen I, Pamplona, Fundación Diario de Navarra.

VV.AA. (1994), El Camino de Santiago y la articulación del espacio hispánico. XX Semana de Estudios Medievales de Estella, Pamplona, Gobierno de Navarra.

VV.AA. (1994), IV Semana de Estudios Medievales, Logroño, Instituto de Estudios Riojanos.

VV.AA. (2006), El comercio en la Edad Media. XVI Semana de Estudios Medievales, Logroño, Instituto de Estudios Riojanos. 